\title{
Correction to: Applications of hepatic round ligament/falciform ligament flap and graft in abdominal surgery-a review of their utility and efficacy
}

\author{
Vasudevan Baskaran ${ }^{1}$ - Jayant Kumar Banerjee ${ }^{2}$. Sita Ram Ghosh ${ }^{3}$. Sukumar Santosh Kumar ${ }^{4}$. \\ Subramaniam Anand ${ }^{5} \cdot$ Govind Menon $^{6} \cdot$ Deep Shikha Mishra ${ }^{5} \cdot$ Ramanathan Saranga Bharathi ${ }^{4}$
}

Published online: 8 March 2021

(C) Springer-Verlag GmbH Germany, part of Springer Nature 2021

Correction to: Langenbeck's Archives of Surgery (2020) https://doi.org/10.1007/s00423-020-02031-6

The original version of this article unfortunately contained a few mistakes.

The original article has been corrected.

Publisher's note Springer Nature remains neutral with regard to jurisdictional claims in published maps and institutional affiliations.

The online version of the original article can be found at https://doi.org/ 10.1007/s00423-020-02031-6

Ramanathan Saranga Bharathi sarangabharathi@gmail.com

1 Department of Gastro-intestinal Surgery, MIOT Hospital, Chennai, India

2 Department of Gastro-intestinal Surgery, Bharati Vidyapeeth Medical College, Pune, India

3 Department of Gastro-intestinal Surgery, Command Hospital (Eastern Command), Kolkata, India

4 Department of Gastro-intestinal Surgery, Command Hospital (Central Command), Lucknow, Uttar Pradesh 226002, India

5 Department of Surgery, Armed Forces Medical College, Pune, India

6 Department of Plastic \& Reconstructive Surgery, Command Hospital (Central Command), Lucknow, India 